\title{
Effects of isokinetic muscle strengthening on balance, proprioception, and physical function in bilateral knee osteoarthritis patients with moderate fall risk
}

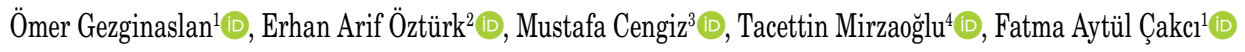 \\ ${ }^{1}$ Department of Physical Medicine and Rehabilitation, University of Health Sciences, Ümraniye Training and Research Hospital, İstanbul, Turkey \\ ${ }^{2}$ Department of Physical Medicine and Rehabilitation, University of Health Sciences, Dışkapı Yıldırım Beyazıt Training and Research Hospital, Ankara, Turkey \\ ${ }^{3}$ Department of Physical Medicine and Rehabilitation, Şrnak State Hospital, Şırnak, Turkey \\ ${ }^{4}$ Department of Physical Medicine and Rehabilitation, Tatvan State Hospital, Bitlis, Turkey
}

Received: December 05, 2017 Accepted: August 27, 2018 Published online: October 09, 2018

\begin{abstract}
Objectives: This study aims to assess the effects of isokinetic quadriceps and hamstring strengthening exercises on balance, proprioception, and physical function in patients with moderate-to-severe knee osteoarthritis and moderate fall risk.

Patients and methods: Between November 2011 and December 2012, a total of 39 participants (30 females, 9 males; mean age $61.7 \pm 8.6$ years; range, 18 to 79 years) with Grade 2 or 3 knee osteoarthritis according to the Kellgren-Lawrence radiographic grading system and moderate risk of fall with active knee pain were included in this study. All participants received isokinetic quadriceps and hamstring strengthening exercises for six weeks. Pre-treatment quadriceps and hamstring muscle strength (peak torque and total work value) and quadriceps to hamstring muscle strength ratio at angular velocities of $60 \% \mathrm{sec}$ and $180 \% \mathrm{sec}$, range of motion (ROM), average proprioceptive errors at $15-45^{\circ}$ and $30-60^{\circ}$, the Berg Balance Scale (BBS) scores, the Western Ontario and McMaster Universities Osteoarthritis Index (WOMAC) subscale scores, the Visual Analog Scale (VAS) scores, and physical function tests results were compared with the post-treatment results. The correlations of pre- and post-treatment BBS and average proprioceptive error at $15-45^{\circ}$ and $30-60^{\circ}$ changes to other pre- and post-treatment clinical measurements changes were calculated.
\end{abstract}

Results: Post-treatment quadriceps and hamstring muscle strength at angular velocities of $60 \% \mathrm{sec}$ and $180 \%$ sec and quadriceps to hamstring muscle strength ratios at angular velocity of $60^{\circ} \mathrm{sec}$, ROM, average proprioceptive errors at $15-45^{\circ}$ and $30-60^{\circ}$, BBS scores, WOMAC subscale scores, VAS scores, and physical function tests significantly improved compared to the pre-treatment results ( $\mathrm{p}<0.001)$. Statistically significant correlations were found between the pre- and post-treatment BBS score changes and pre- and post-treatment VAS ( $\mathrm{p}=0.015$ ), WOMAC-Pain ( $\mathrm{p}=0.017)$, WOMAC-Physical Function $(\mathrm{p}=0.005)$ scores and Timed Up and Go Test $(\mathrm{p}=0.036)$ scores.

Conclusion: Inclusion of isokinetic quadriceps and hamstring strengthening exercises into the rehabilitation programs for the patients with knee osteoarthritis may improve the quality of life and contribute to the decreased risk of fall.

Keywords: Balance; isokinetic muscle strengthening; osteoarthritis; proprioception.

Osteoarthritis (OA) is a slowly progressive degenerative joint disease characterized by the destruction of articular cartilage and remodeling of the periarticular bone. Symptomatic OA with a prevalence of 5 to $7 \%$ in the adult population is a common chronic disease leading to functional impairment. ${ }^{[1]}$ The knee joint is the most commonly affected joint by symptomatic OA..$^{[2]}$
Many studies have demonstrated that impaired proprioception may cause degenerative joint diseases ${ }^{[3-6]}$ In patients with symptomatic OA, the risk of fall increases due to the combined effect of impaired proprioception and quadriceps to hamstrings muscle strength ratio and balance. ${ }^{[3]}$ Similarly, in a study, increase in the quadriceps muscle strength has shown to decrease the risk of fall. ${ }^{[7]}$ Therefore, improvements

Corresponding author: Ömer Gezginaslan, MD. SBÜ Ümraniye Eğitim ve Araştırma Hastanesi Fiziksel Tıp ve Rehabilitasyon Kliniği, 34764 Ümraniye, İstanbul, Turkey. 
in proprioception, balance and physical function have a significant role in increased quality of life due to the decreased risk of fall in OA patients. There are several studies showing that isokinetic muscle strengthening exercises improve proprioception, balance and physical function. ${ }^{[8-14]}$

In this study, we aimed to assess the effect of quadriceps and hamstring strengthening on proprioception, balance, and physical function specifically in patients with Grade 2 or 3 knee OA, according to the Kellgren-Lawrence (KL) radiographic grading system and moderate risk of fall.

\section{PATIENTS AND METHODS}

This prospective clinical study was conducted at Dışkapı Yıldırım Beyazıt Training and Research Hospital between November 2011 and December 2012. A written informed consent was obtained from each participant. The study protocol was approved by the local Ethics Committee. The study was conducted in accordance with the principles of the Declaration of Helsinki.

A total of 39 participants ( 30 females, 9 males; mean age $61.7 \pm 8.6$ years; range, 18 to 79 years) with Grade 2 or 3 knee OA according to the KL radiographic grading system and moderate risk of fall with active knee pain were included in this study. All patients attended to the musculoskeletal outpatient clinic for knee pain. Inclusion criteria were as follows: (i) diagnosis of primary OA according to the American College of Rheumatology (ACR) criteria, ${ }^{[15]}$ (ii) Grade 2 or 3 bilateral OA according to the KL radiographic grading system, (iii) history of fall and Berg Balance Scale (BBS) score ${ }^{[16,17]}$ between 20 and 40, (iv) Mini-Mental Test (MMT) score of $\geq 23,{ }^{[18,19]}$ and $(v)$ active knee pain in the last month (Visual Analog Scale [VAS] score $>3$ ) ${ }^{[20]}$ Exclusion criteria were as follows: (i) diagnosis of secondary OA, (ii) severe knee trauma, knee surgery, intraarticular knee joint injections of hyaluronic acid and/or steroids in the last six months, (iii) presence of active synovitis, (iv) any concurrent neurological (i.e., Parkinson's disease, Alzheimer's dementia, or polyneuropathy), endocrine (i.e., diabetes mellitus) and/or vestibular disorders which may affect physical function, pain or joint proprioception, $(v)$ an advanced chronic disease which may affect general health status (i.e., heart failure, chronic obstructive lung disease, and cancer), (vi) any hearing or visual impairment, (vii) any chronic inflammatory disorder of the knee joint (i.e., rheumatoid arthritis, ankylosing spondylitis, psoriatic arthritis, and chronic reactive arthritis).
Sociodemographic data of each participant were recorded. Subsequently, all patients underwent comprehensive physical examination and range of motion (ROM) measurement by a rehabilitation specialist using a standard goniometer. The MMT was performed by a psychologist. The VAS and Western Ontario and McMaster Universities Osteoarthritis Index-Pain (WOMAC-P ${ }^{[21,22]}$ were used to assess pain; the WOMAC-Physical Function (WOMAC-PF), Timed Up and Go Test (TUG), Five Times Sit to Stand Test (5XSST), and Six-Minute Walk Test (6MWT) were used to assess physical function; the WOMAC-Stiffness (WOMAC-S) was used for joint stiffness and BBS was used to assess balance. The muscle strength at angular velocities of $60 \% \mathrm{sec}$ and $180 \% \mathrm{sec}$ and average proprioceptive errors at $15-45^{\circ}$ and $30-60^{\circ}$ were assessed using the Biodex System 3 Pro Multi-Joint System (Biodex Medical Systems; Shirley, NY, USA) isokinetic dynamometer. All assessments were repeated following the completion of the exercise program. The body mass index (BMI) was calculated as $\mathrm{kg} / \mathrm{m}^{2}$.

The MMT is an easily applicable 30-point questionnaire used to measure cognitive impairment. Scores that are equal or greater than 23 shows normal cognition. ${ }^{[17,18]}$ The VAS score ranges from 0 to 10 with 0 indicating no pain and 10 indicating the most severe pain ever experienced. ${ }^{[20]}$

The WOMAC is used to assess pain, stiffness, and physical function. ${ }^{[21,23]}$ All participants were asked to rate the pain at five activities, stiffness at two situations and physical function at 17 activities.

The BBS is used to assess a person's balance abilities while performing functional tasks. ${ }^{[16,17]}$ It comprises 14 items and a score was given from 0 (unable) to 4 (independent) for each item. Based on the total score obtained from this test, the results were interpreted as follows: "high risk of fall" (0-20 points); "moderate risk of fall" (21-40 points); "low risk of fall" (41-56 points). ${ }^{[23,24]}$ The Turkish validity and reliability of all the tests were checked.

The TUG was used to assess functionality. The participants were asked to stand up from a standard chair when they hear the start command, walk three meter at a steady pace, turn around, walk back and sit down. The required time to perform this task was recorded in sec using a stopwatch. ${ }^{[25]}$

Using the 5XSST, the participants were asked to sit with their back against the back of the chair and arms folded across their chest, stand up from the chair and sit down five times as quickly as they could. 
A stopwatch was started at the start command and stopped at the moment that they sit the chair for the last time. ${ }^{[26]}$

The $6 \mathrm{MWT}$ is an objective index of exercise tolerance. ${ }^{[27,28]}$ It is easy to perform without requiring any special equipment. A 30-meter long hallway was marked with three-meter intervals and a stopwatch was used during the test. The participants were instructed to wear comfortable clothing and appropriate shoes. A light meal was allowed and all were advised not to exercise vigorously within two hours of the beginning of the test. Blood pressure and pulse measurements were performed before and after the test. The participants were asked to walk across the 30-meter long hallway for six minutes and were allowed to use their usual walking aids such as cane. Following the completion of the test, the distance walked was recorded in meters. The walking speed was calculated in meters per sec.

\section{Isokinetic assessment}

The isokinetic muscle strength was assessed using the isokinetic dynamometer. Accessories appropriate for the extension and flexion of the knee joint were mounted on the device, and the device was checked for calibration errors. The participants were provided information with respect to how the test would be conducted and its purposes.

The participants were instructed to sit with backrest at a $90^{\circ}$ angle on the chair and gripped the sides of the chair simultaneously. The body and thigh were stabilized by stabilization straps and foot were positioned in the lever arm and stabilized at the malleolar level. During the test, angular velocities of $60 \% \mathrm{sec}$ and $180 \% \mathrm{sec}$ were preferred as being commonly used angular velocities. The test was started at maximum flexion and followed by several submaximal repetitions to warm up. The knee was flexed to $90^{\circ}$ and remained in this position for $10 \mathrm{sec}$. The participants completed three maximal repetitions at an angular velocity of $60 \% \mathrm{sec}$ and 3 maximal repetitions at an angular velocity of $180 \% \mathrm{sec}$. Angular velocities were changed after 20 -sec rest intervals. The data obtained from the measurements at two angular velocities and included in the analyses were as follows: quadriceps peak torque (PT) value (newton-meter), hamstring PT value (newton-meter), quadriceps to hamstring ratio, and hamstring-quadriceps total work (TW) values (joules).

Proprioception was assessed using the isokinetic dynamometer. Measurements were performed at constant ambient temperature and in a quiet medium. Isokinetic dynamometer set-up was mentioned above.
A trial was conducted with eyes open. Initially, the leg was positioned at the reference angle of $15^{\circ}$ for $10 \mathrm{sec}$. Then, the participants were blindfolded. The knee was passively flexed $45^{\circ}$ and the participants were asked to memorize this position. The knee remained in this position for $10 \mathrm{sec}$, and the leg was passively repositioned at the reference angle of $15^{\circ}$ and remained in this position to rest for $10 \mathrm{sec}$. Then, the subjects were asked to place their leg at the memorized angle by themselves. Once the subjects placed their legs at the angle that they memorized, the angle reached was recorded. The same procedure was repeated for reference angle of $30^{\circ}$ and target angle of $60^{\circ}$. The measurements were repeated three times with fivemin intervals and the average of three values were calculated. The difference between the calculated values and actual target values was found and the average proprioceptive error was calculated without taking into consideration that whether this value was positive or negative.

\section{Interventions}

The participants were instructed not to use non-steroidal anti-inflammatory drugs during the study. After the calculation of isokinetic muscle strength, quadriceps to hamstring ratio and average proprioceptive error, the patients were given isokinetic muscle strengthening exercises three times a week for six weeks. The participants performed 10 concentric-concentric flexion and extension contractions at $45 \% \mathrm{sec}, 60 \% \mathrm{sec}, 75 \% \mathrm{sec}$, $90 \% \mathrm{sec}, 120 \% \mathrm{sec}, 150 \% \mathrm{sec}$ and $180 \% \mathrm{sec}$ angular velocity. Twenty-sec rests were allowed between each angular velocity. Five-min rest was allowed between the right and left knees.

\section{Statistical analysis}

Statistical analysis was performed using IBM SPSS version 23.0 software (IBM Corp., Armonk, NY, USA). The Shapiro-Wilk test was used to analyze whether the continuous variables were normally distributed. Normally distributed data were compared using the dependent t-test. Nonnormally disturbed were compared using the Wilcoxon signed-rank test. Descriptive statistics for continuous variables were expressed in mean \pm standard deviation (SD) and median (min-max) values, while the categorical variables were expressed in number and percent. The dependent t-test was used to compare mean pre-treatment and post-treatment measurements. The Wilcoxon signed-rank test was used to compare median 
pre-treatment and post-treatment measurements. The Spearman's correlation test was used to correlate continuous variables. The post-hoc power analysis was performed to identify the power of the study using $G^{\star}$ Power version 3.1.9.2. A $p$ value of $<0.05$ was considered statistically significant.

Table 1. Demographic and clinical characteristics of patients

\begin{tabular}{|c|c|c|c|c|c|}
\hline & $\mathrm{n}$ & $\%$ & Mean \pm SD & Median & IQR \\
\hline Age (year) & & & $61.7 \pm 8.6$ & & \\
\hline \multicolumn{6}{|l|}{ Sex } \\
\hline Male & 9 & 23.1 & & & \\
\hline Female & 30 & 76.9 & & & \\
\hline Weight $(\mathrm{kg})$ & & & $79.3 \pm 8.6$ & & \\
\hline Height (m) & & & $1.59 \pm 0.09$ & & \\
\hline Body Mass Index $\left(\mathrm{kg} / \mathrm{m}^{2}\right)$ & & & $31.7 \pm 5.4$ & & \\
\hline Duration of the disease (month) & & & & 36 & $1-120$ \\
\hline Mini-Mental Test & & & & 27 & $20-30$ \\
\hline
\end{tabular}

SD: Standard deviation; IQR: Interquartile range.

Table 2. Pre- and post-treatment K-L grades, ROM, and walking speed measurements, BBS, TUG, 6MWT, 5XSST, VAS, WOMAC A, S and PF scores

\begin{tabular}{|c|c|c|c|c|c|c|c|c|c|c|}
\hline & \multicolumn{3}{|c|}{ Pre-treatment } & \multicolumn{3}{|c|}{ Post-treatment } & \multirow[b]{2}{*}{$p$} & \multicolumn{3}{|c|}{ Change } \\
\hline & Mean \pm SD & Median & IQR & Mean \pm SD & Median & IQR & & Mean \pm SD & Median & IQR \\
\hline K-L & & 2 & $2-3$ & & 2 & $2-3$ & 1.000 & & 0 & $0-0$ \\
\hline $\mathrm{ROM}\left(^{\circ}\right)$ & $109.0 \pm 11.3$ & & & $117.5 \pm 10.2$ & & & $<0.001^{\star}$ & $8.5 \pm 6.1$ & & \\
\hline BBS & & 35 & $25-39$ & & 38 & $30-43$ & $<0.001^{\star}$ & & 2 & $1-8$ \\
\hline $\begin{array}{l}\text { Walking speed } \\
\quad(\mathrm{m} / \mathrm{sec})\end{array}$ & & 0.93 & $0.28-1.8$ & & 1.1 & $0.5-2.3$ & $<0.001^{\star}$ & & 0.2 & $0.04-0.9$ \\
\hline TUG (sec) & & & 8.9 & $6.4-46$ & 7.2 & $5.4-13.4$ & $<0.001^{\star}$ & & -1.4 & $-34.8--0.1$ \\
\hline 6MWT (sec) & & & 336 & $102-622$ & 408 & $196-812$ & $<0.001^{\star}$ & & 68 & $12-308$ \\
\hline VAS $(\mathrm{cm})$ & & & 70 & $30-100$ & 20 & $0-80$ & $<0.001^{*}$ & & -40 & $-70--10$ \\
\hline WOMAC-P & & & 3 & $1.8-4.4$ & 1.8 & $0.8-3$ & $<0.001^{*}$ & & -1.2 & $-2.4--0.4$ \\
\hline WOMAC-S & & & 3 & $1.5-4$ & 1 & $1-2$ & $<0.001^{\star}$ & & -1 & $-2-0$ \\
\hline WOMAC-PF & & & 3 & $1.75-4.1$ & 2 & $1-2.6$ & $<0.001^{*}$ & & -1.1 & $-2.5--0.2$ \\
\hline
\end{tabular}

SD: Standard deviation; IQR: Interquartile range; K-L: Kellgen-Lawrence; ROM: Range of motion; BBS: Berg balance scale; TUG: Timed up and go test; 6MWT: Six-minute walk test; 5XSST: Five times sit to stand test; VAS: Visual Analog Scale; WOMAC-P: Western Ontario and McMaster Universities Osteoarthritis Index-Pain; WOMAC-S: Western Ontario and McMaster Universities Osteoarthritis Index-Stiffness; WOMAC-PF: Western Ontario and McMaster Universities Osteoarthritis Index-Physical Function; ${ }^{*} \mathrm{p}<0.05$, significant difference between the pre- and post-treatment results; Mean \pm SD: The $p$ value corresponds to dependent $\mathrm{t}$-test comparing the pre- and post-treatment measurements; Median (IQR): The $p$ value corresponds to the Wilcoxon signed-rank test comparing the pre- and post-treatment measurements.

Table 3. Pre- and post-treatment PT and TW measurements in flexion and extension at angular velocities of $60 \%$ sec and $180 \% \mathrm{sec}$

\begin{tabular}{|c|c|c|c|c|c|c|c|}
\hline & \multicolumn{2}{|c|}{ Pre-treatment } & \multicolumn{2}{|c|}{ Post-treatment } & \multirow[b]{2}{*}{$p^{*}$} & \multicolumn{2}{|c|}{ Change } \\
\hline & Median & IQR & Median & IQR & & Median & IQR \\
\hline PT-E $\left(180^{\circ} / \mathrm{sec}\right)^{* *}$ & 34.8 & $20.7-71.7$ & 50.8 & $23.1-110.6$ & $<0.001$ & 12.7 & $-3.8-43.7$ \\
\hline PT-F $\left(180^{\circ} / \mathrm{sec}\right)^{* *}$ & 15.7 & $8.7-43.8$ & 24.5 & $14-72$ & $<0.001$ & 7.1 & $-9.8-44.1$ \\
\hline TW-E $\left(180^{\circ} / \mathrm{sec}\right)^{* *}$ & 242 & $110.8-1146.7$ & 367.8 & $98.9-1041.6$ & $<0.001$ & 76.6 & $-105.1-462.3$ \\
\hline TW-F $\left(180^{\circ} / \mathrm{sec}\right)^{\star *}$ & 26.4 & $1.9-398.8$ & 97.5 & $8.1-617.2$ & $<0.001$ & 56.5 & $-97.9-411.9$ \\
\hline PT-E $\left(60^{\circ} / \mathrm{sec}\right)^{* *}$ & 61.2 & $20.2-124.1$ & 72.1 & $43.2-156.8$ & $<0.001$ & 14.1 & $-22.6-63.8$ \\
\hline PT-F $\left(60^{\circ} / \mathrm{sec}\right)^{* *}$ & 20.1 & $7.2-59.7$ & 32.1 & $12.0-91.1$ & $<0.001$ & 12.8 & $-15.6-63.7$ \\
\hline TW-E $\left(60^{\circ} / \mathrm{sec}\right)^{* *}$ & 242.9 & $95.8-504.4$ & 300.9 & $173.6-552.1$ & $<0.001$ & 65.1 & $-251-250.6$ \\
\hline TW-F $\left(60^{\circ} / \mathrm{sec}\right)^{* *}$ & 68.8 & $0.3-326.3$ & 127.9 & $19.1-505.1$ & $<0.001$ & 72.1 & $-64.3-240.4$ \\
\hline
\end{tabular}

PT: Peak torque; TW: Total work; IQR: Interquartile range; PT-E: Peak torque-extension; PT-F: Peak torque-flexion; TW-E: Total work-extension; TW-F: Total work-flexion; ${ }^{\star}$ $\mathrm{p}<0.05$ : Significant difference between the pre- and post-treatment results; ${ }^{* *}$ Data are presented in median (IQR). The $\mathrm{p}$ value corresponds to the Wilcoxon signed-rank test comparing the pre- and post-treatment measurements. 


\section{RESULTS}

Our sample of 39 participants provided a power of $86.1 \%$ at a significance level of $5 \%$ and an effect size of 0.5 . We used pre- and post-treatment agonist-to-antagonist ratio at an angular velocity of $60 \% \mathrm{sec}$ to calculate the effect size. The mean BMI was $31.7 \pm 5.4 \mathrm{~kg} / \mathrm{m}^{2}$ and the mean MMT score was 27 (range, 23 to 30). Clinical and demographic characteristics of the patients are shown in Table 1.

Table 4. Pre- and post-treatment agonist-to-antagonist ratio at angular velocities of 60 and $180 \%$ sec and average proprioceptive error at $15-45^{\circ}$ and $30-60^{\circ}$

\begin{tabular}{|c|c|c|c|c|c|c|c|c|c|c|}
\hline & \multicolumn{3}{|c|}{ Pre-treatment } & \multicolumn{3}{|c|}{ Post-treatment } & \multirow[b]{2}{*}{$p$} & \multicolumn{3}{|c|}{ Change } \\
\hline & Mean \pm SD & Median & IQR & Mean \pm SD & Median & IQR & & Mean \pm SD & Median & IQR \\
\hline $\begin{array}{l}\text { Agonist/antagonist } \\
\left(180^{\circ} / \mathrm{sec}\right) \dagger\end{array}$ & $51.3 \pm 13.2$ & & & $54.8 \pm 15.3$ & & & 0.259 & $3.5 \pm 19.1$ & & \\
\hline $\begin{array}{l}\text { Agonist/antagonist } \\
\left(60^{\circ} / \mathrm{sec}\right) \dagger\end{array}$ & $37.6 \pm 12.6$ & & & $47.7 \pm 14.5$ & & & $<0.001^{*}$ & $10.1 \pm 12.0$ & & \\
\hline $\begin{array}{l}\text { Average } \\
\text { proprioceptive error } \\
\left(15-45^{\circ}\right) \ddagger\end{array}$ & & 7.2 & $3-17.1$ & & 5.1 & $2.2-9.2$ & $<0.001^{\star}$ & & -1.9 & $-12.6-1.3$ \\
\hline $\begin{array}{l}\text { Average } \\
\text { proprioceptive error } \\
\left(30-60^{\circ}\right) \ddagger\end{array}$ & & 4.3 & $1.8-13.6$ & & 3.3 & $1.7-6.5$ & $<0.001^{*}$ & & -1.1 & $-11.1-1.3$ \\
\hline
\end{tabular}

SD: Standard deviation; IQR: Interquartile range; ${ }^{\star} \mathrm{p}<0.05$, significant difference between the pre- and post-treatment results; $\dagger$ Data are presented in mean $(\mathrm{SD})$. The $p$ value corresponds to dependent t-test comparing the pre- and post-treatment measurements; $\ddagger$ Data are presented in median (IQR). The $\mathrm{p}$ value corresponds to Wilcoxon signed-rank test comparing the pre- and post-treatment measurements.

Table 5. Correlations of changes in BBS and average proprioceptive error at $15-45^{\circ}$ and $30-60^{\circ}$ to changes in other clinical measurements after treatment and MMT

\begin{tabular}{|c|c|c|c|c|c|c|}
\hline & \multicolumn{2}{|c|}{$\begin{array}{l}\text { Average proprioceptive } \\
\text { error at } 15-45^{\circ}\end{array}$} & \multicolumn{2}{|c|}{$\begin{array}{l}\text { Average proprioceptive } \\
\text { error at } 30-60^{\circ}\end{array}$} & \multicolumn{2}{|c|}{ Berg Balance Scale } \\
\hline & $\mathrm{r}$ & $p$ & $\mathrm{r}$ & $p$ & $\mathrm{r}$ & $p$ \\
\hline Agonist/antagonist $\left(180^{\circ} / \mathrm{sec}\right) \dagger$ & -0.008 & 0.963 & 0.281 & 0.083 & -0.016 & 0.923 \\
\hline Agonist/antagonist $(60 \% \mathrm{sec}) \dagger$ & 0.060 & 0.715 & 0.018 & 0.912 & -0.103 & 0.533 \\
\hline PT-E $\left(180^{\circ} / \mathrm{sec}\right) \dagger$ & 0.008 & 0.962 & 0.063 & 0.705 & 0.134 & 0.417 \\
\hline PT-F $\left(180^{\circ} / \mathrm{sec}\right) \dagger$ & 0.083 & 0.615 & 0.092 & 0.579 & 0.065 & 0.695 \\
\hline TW-E $\left(180^{\circ} / \mathrm{sec}\right) \dagger$ & 0.112 & 0.495 & 0.186 & 0.257 & 0.295 & 0.068 \\
\hline TW-F $\left(180^{\circ} / \mathrm{sec}\right) \dagger$ & 0.006 & 0.969 & 0.142 & 0.388 & 0.167 & 0.308 \\
\hline PT-E $(60 \%$ sec $) \dagger$ & 0.225 & 0.169 & 0.211 & 0.198 & 0.127 & 0.440 \\
\hline PT-F $\left(60^{\circ} / \mathrm{sec}\right) \dagger$ & 0.232 & 0.155 & 0.124 & 0.452 & -0.052 & 0.753 \\
\hline TW-E $\left(60^{\circ} / \mathrm{sec}\right) \dagger$ & 0.159 & 0.333 & 0.051 & 0.756 & 0.263 & 0.106 \\
\hline TW-F $(60 \%$ sec $) \dagger$ & 0.161 & 0.327 & 0.220 & 0.179 & 0.064 & 0.697 \\
\hline WOMAC-P $\dagger$ & 0.274 & 0.092 & 0.278 & 0.087 & -0.379 & $0.017^{\star}$ \\
\hline WOMAC-S $\dagger$ & 0.122 & 0.461 & 0.010 & 0.952 & -0.246 & 0.131 \\
\hline WOMAC-PF $\dagger$ & 0.160 & 0.330 & 0.046 & 0.779 & -0.442 & $0.005^{*}$ \\
\hline Walking speed $(\mathrm{m} / \mathrm{sec}) \dagger$ & 0.067 & 0.684 & -0.033 & 0.841 & -0.089 & 0.590 \\
\hline TUG (sec) $\dagger$ & 0.200 & 0.223 & 0.041 & 0.803 & -0.336 & $0.036^{*}$ \\
\hline $6 \mathrm{MWT}(\mathrm{sec}) \dagger$ & 0.022 & 0.896 & -0.096 & 0.561 & -0.135 & 0.413 \\
\hline $5 \mathrm{XSST}(\mathrm{sec}) \dagger$ & 0.226 & 0.166 & 0.003 & 0.987 & -0.061 & 0.714 \\
\hline $\operatorname{ROM}\left(^{\circ}\right) \dagger$ & -0.165 & 0.314 & -0.221 & 0.175 & 0.262 & 0.107 \\
\hline $\operatorname{VAS}(\mathrm{cm}) \dagger$ & 0.295 & 0.068 & 0.089 & 0.592 & -0.386 & $0.015^{*}$ \\
\hline MMT $\dagger$ & 0.505 & $<0.001^{\star}$ & 0.294 & 0.069 & -0.066 & 0.691 \\
\hline
\end{tabular}

BBS: Berg Balance Scale; MMT: Mini-Mental Test; PT-E: Peak torque-extension; PT-F: Peak torque-flexion; TW-E: Total work-extension; TW-F: Total work-flexion; WOMAC-P: Western Ontario and McMaster Universities Osteoarthritis Index-Pain; WOMAC-S: Western Ontario and McMaster Universities Osteoarthritis Index-Stiffness; WOMAC-PF: Western Ontario and McMaster Universities Osteoarthritis Index-Physical Function; TUG: Timed up and go test; 6MWT: Six minute walk test; 5XSST: Five times sit to stand test; ROM: Range of motion; VAS: Visual analog scale; ${ }^{*} \mathrm{p}<0.05$, significant difference between the pre- and post-treatment results; $\uparrow$ Spearman's correlation test was used to analyze correlations. 
Post-treatment ROM measurements and 6MWT results were improved significantly compared to pre-treatment values $(\mathrm{p}<0.001)$. Post-treatment TUG, 5XSST results and BBS, VAS, WOMAC-Pain (WOMAC-P), WOMAC-Stiffness (WOMAC-S), WOMAC-Physical Function (WOMAC-PF) scores significantly decreased, compared to pre-treatment values $(\mathrm{p}<0.001)$ (Table 2$)$.

Post-treatment PT and TW values during flexion and extension at angular velocities of $60 \% \mathrm{sec}$ and $180 \%$ sec significantly increased, compared to the pre-treatment values $(\mathrm{p}<0.001)$ (Table 3$)$.

The post-treatment agonist-to-antagonist ratio at an angular velocity of $60 \% \mathrm{sec}$ significantly increased, compared to the pre-treatment values $(\mathrm{p}<0.001)$, whereas the increase in the post-treatment agonistto-antagonist ratio at an angular velocity of $180 \%$ sec was not statistically significant $(p=0.259)$. The post-treatment average proprioceptive errors at $15-45^{\circ}$ and $30-60^{\circ}$ significantly decreased, compared to the pre-treatment values $(\mathrm{p}<0.001)$ (Table 4$)$.

There were statistically significant, but poor negative correlations between the change in BBS, and both changes in the WOMAC-P $(\mathrm{r}=-0.379)$ and TUG $(\mathrm{r}=-0.336)$ after treatment. There was a statistically significant and moderate negative correlation between change in BBS and change in WOMAC-PF $(r=-0.442)$ after treatment. There was statistically significant and moderate positive correlation between change in the average proprioceptive error at $15-45^{\circ}$ after treatment and MMT scores ( $r=0.505)$ (Table 5).

\section{DISCUSSION}

The primary objective of this study was to investigate the relationship between knee joint proprioception, hamstrings and quadriceps muscle strengths, physical function and balance in OA patients with moderate risk of fall. The study results demonstrated that quadriceps and hamstring strengthening in a six-week program of regular isokinetic exercise had significant effects on balance, proprioception and physical function even in patients who has KL Grade 2 or 3 OA with moderate risk of fall (BBS score of 21-40). Thus, we suggest that there is a relationship between balance, proprioception, and quadriceps and hamstring muscle strengths in OA patients.

In this study, significant changes were observed both in the ROM and in WOMAC subscale scores. Steultjens et al. ${ }^{[1]}$ demonstrated that knee ROM in OA patients was a significant risk factor for disability.
A total of $25 \%$ of the post-treatment change in functionality and disability scores such as WOMAC were linked to the ROM changes. ${ }^{[1]}$ Therefore, changes in some of the WOMAC subscale scores may be attributed to the improvement in ROM.

Loss or impairment of proprioception was reported to be associated with a decreased gait speed, a decreased total duration of walking, and impaired gait rhythm in OA patients. ${ }^{[29-31]}$ In addition, Sharma et al. ${ }^{[32]}$ analyzed the association between proprioceptive precision and physical function in patients with OA and found a significant association between proprioception and the 5XSST results. In a study conducted by Bouët et al., ${ }^{[12]}$ cycling exercises were found to be associated with an improved proprioception. Van der Esch et al. ${ }^{[14]}$ conducted a study in $33 \mathrm{OA}$ patients aged between 45 and 79 years and reported a significant correlation between functional deterioration and both impaired knee proprioception and decreased quadriceps and hamstrings muscle strength. In our study, isokinetic exercises were associated with significant improvements in both average proprioceptive errors and function tests. Based on these findings, overall muscle strengthening exercises may increase physical function by improving proprioception in patients with OA.

Whipple et al. ${ }^{[13]}$ compared patients with a history of fall to the patients without a history of fall regarding the strength of knee flexors, knee extensors, ankle dorsiflexors and plantar flexors. The strength of all of the examined muscles was found to be significantly lower in patients with a history of fall, compared to the patients without a history of fall. In our study, significant improvements in quadriceps and hamstring muscle strength due to isokinetic exercises led to the improvements in BBS. Furthermore, a statistically significant correlation was found between the improvement in BBS scores and pain/functionality. Improvement in balance may improve the quality of life, by reducing pain and increasing functionality.

In a study including 95 elderly patients, Lord et al. ${ }^{[33]}$ reported that impaired proprioception and impaired vibration sense substantially affected postural stability. Colledge et al. ${ }^{[34]}$ also reported that impaired proprioception substantially affected postural stability. Our study showed that isokinetic exercises improved proprioception and balance at the same time. This finding further supports the fact that isokinetic exercises improve both balance and proprioception. 
In their study, Berg et al. ${ }^{[24]}$ reported that a BBS score equal or less than 40 was an important risk factor in terms of prediction of fall risk. Our study demonstrated that, in patients with BBS scores between 20-40 (moderate fall risk), isokinetic strengthening exercises contributed to the improved balance and reduced number of falls. The inclusion of the patients in this study with BBS scores between 20-40 better emphasized the effects of muscle strengthening exercises on balance and falls.

In a study including 104 patients with knee OA who were candidates for knee arthroplasty, Pua et al..$^{[35]}$ found a significant association between balance and physical function which was dependent on the knee extensor strength. Similarly, in our study, we found that muscle strengthening exercises improved balance, walking speed, and physical function.

In a study conducted by Kim et al., ${ }^{[36]}$ impaired balance and postural instability were reported in patients with knee OA. In our study, significant balance improvements were observed in OA patients with impaired balance following isokinetic strengthening of quadriceps and hamstring muscles. These results emphasized the importance of quadriceps and hamstrings strengthening in patients with OA.

Samut et al. ${ }^{[8]}$ found a significant decrease in the VAS and WOMAC subscores and a significant increase in the functionality and muscle strength in both isokinetic end aerobic exercise group. This study and our study support that regular muscle strengthening exercises improve functionality and reduce pain.

In their study, Tuna et al. ${ }^{[9]}$ investigated whether femoral cartilage thickness changed with muscle strengthening exercises. The authors found a positive correlation between the femoral cartilage thickness and muscle strength at three months. They also found a significant decrease in the VAS scores; however, they failed to show a significant change in the WOMAC subscores with isokinetic exercises. ${ }^{[9]}$ One of the limitations of this study was that the patients performed only a single day of isokinetic exercise program with $30 \% \mathrm{sec}, 60 \% \mathrm{sec}, 90 \% \mathrm{sec}$ and $180 \% \mathrm{sec}$ angular velocities. Then, the patients moved on a home-based exercise program. This may be insufficient to improve the WOMAC subscores. In our study, the patients performed isokinetic exercise program with $45 \% \mathrm{sec}, 60 \% \mathrm{sec}, 75 \% \mathrm{sec}, 90 \% \mathrm{sec}, 120 \% \mathrm{sec}, 150 \% \mathrm{sec}$ and $180 \%$ sec angular velocities three times a week for six weeks. A more intensive exercise program may be more helpful in terms of WOMAC subscores. Overall isokinetic exercise programs may be useful in different ways such as femoral cartilage thickness in OA patients.

A study conducted by Kucuk et al., ${ }^{[10]} 45$ OA patients were divided into three exercise groups (isokinetic, isometric, and aerobic) and exercises were given five days a week for four weeks. They found improvements in the VAS, WOMAC, Lequesne scores, and quadriceps $\mathrm{PT}$ values in all groups with the highest improvement in isokinetic exercise group. They found a significant improvement in the hamstring muscle strength only in the isokinetic group. The Hamstring-to-quadriceps ratio remained unchanged in the isokinetic group, whereas this ratio decreased in other groups. ${ }^{[10]}$ In our study, we found significant improvements in the VAS, WOMAC subscores, hamstring, quadriceps PT values and, even in hamstring-to-quadriceps ratio after isokinetic exercises. It is possible that a more intensive exercise program can be effective in more parameters.

Ay et al. ${ }^{[37]}$ conducted a study with three groups in which 60 knee OA patients received homebased strengthening exercise program. They found statistically significant improvements in the VAS, WOMAC subscores, and functional tests after a three-month exercise program. ${ }^{[37]}$ Similarly, we found significant improvements in the VAS, WOMAC subscores, and functional tests after isokinetic strengthening program. This finding highlights the importance of strengthening exercises in reducing pain and stiffness and improving functionality.

In a study conducted by Bugdayci et al., ${ }^{[38]} 147$ knee OA patients were divided into two groups as faller and non-faller. They found that WOMAC subscores were significantly worse in patients with a fall history than patients without a fall history. In our study, the patients were given a isokinetic strengthening exercise program. We found significantly improvements in the WOMAC-P, WOMAC-S and WOMAC-PF, and balance of OA patients. This finding shows the effect of balance over pain, stiffness, and physical function. The muscle strengthening exercise can improve balance by reducing pain and stiffness and increasing physical function.

In our study, a potential effect of cognitive functions on the test results was also taken into consideration. The MMT was administered to each participant by our clinical psychologist and a significant correlation was found between the MMT scores and changes in the average proprioceptive errors at $15-45^{\circ}$. These results suggested that cognitive functions might have affected the test results. 
On the other hand, this study has some limitations. Since patients with KL Grade 1 and 4 OA patients were excluded, our results cannot be generalized to all OA patients. In addition, joint position test used in our study did not cover all aspects of proprioception. Also, further large-scale studies including a control group receiving no exercise intervention may strengthen the results.

In conclusion, balanced strengthening of knee flexors and extensors in patients with knee OA may result in improvements with respect to pain, stiffness, ROM, balance, proprioception and functionality, and in a decrease in the risk of fall. Balanced strengthening of knee flexors and extensors exercises can be eligible therapeutic options for knee OA patients. However, long-term studies with a larger sample size are required to confirm these findings.

\section{Declaration of conflicting interests}

The authors declared no conflicts of interest with respect to the authorship and/or publication of this article.

\section{Funding}

The authors received no financial support for the research and/or authorship of this article.

\section{REFERENCES}

1. Felson DT, Naimark A, Anderson J, Kazis L, Castelli W, Meenan RF. The prevalence of knee osteoarthritis in the elderly. The Framingham Osteoarthritis Study. Arthritis Rheum 1987;30:914-8.

2. Guccione AA, Felson DT, Anderson JJ, Anthony JM, Zhang Y, Wilson PW, et al. The effects of specific medical conditions on the functional limitations of elders in the Framingham Study. Am J Public Health 1994;84:351-8.

3. Hassan BS, Mockett S, Doherty M. Static postural sway, proprioception, and maximal voluntary quadriceps contraction in patients with knee osteoarthritis and normal control subjects. Ann Rheum Dis 2001;60:612-8.

4. Barrack RL, Skinner HB, Buckley SL. Proprioception in the anterior cruciate deficient knee. Am J Sports Med 1989;17:1-6.

5. Noyes FR, Mooar PA, Matthews DS, Butler DL. The symptomatic anterior cruciate-deficient knee. Part I: the long-term functional disability in athletically active individuals. J Bone Joint Surg Am 1983;65:154-62.

6. Barrett DS, Cobb AG, Bentley G. Joint proprioception in normal, osteoarthritic and replaced knees. J Bone Joint Surg Br 1991;73:53-6.

7. Segal NA, Torner JC, Felson D, Niu J, Sharma L, Lewis CE, et al. Effect of thigh strength on incident radiographic and symptomatic knee osteoarthritis in a longitudinal cohort. Arthritis Rheum 2009;61:1210-7.

8. Samut G, Dinçer F, Özdemir O. The effect of isokinetic and aerobic exercises on serum interleukin- 6 and tumor necrosis factor alpha levels, pain, and functional activity in patients with knee osteoarthritis. Mod Rheumatol 2015;25:919-24.
9. Tuna S, Balcı N, Özçakar L. The relationship between femoral cartilage thickness and muscle strength in knee osteoarthritis. Clin Rheumatol 2016;35:2073-7.

10. Küçük EB, Taşkıran ÖÖ, Tokgöz N, Meray J. Effects of isokinetic, isometric, and aerobic exercises on clinical variables and knee cartilage volume using magnetic resonance imaging in patients with osteoarthritis. Turk J Phys Med Rehab 2018;64:8-16.

11. Steultjens MP, Dekker J, van Baar ME, Oostendorp RA, Bijlsma JW. Range of joint motion and disability in patients with osteoarthritis of the knee or hip. Rheumatology (Oxford) 2000;39:955-61.

12. Bouët V, Gahéry Y. Muscular exercise improves knee position sense in humans. Neurosci Lett 2000;289:143-6.

13. Whipple RH, Wolfson LI, Amerman PM. The relationship of knee and ankle weakness to falls in nursing home residents: an isokinetic study. J Am Geriatr Soc 1987;35:13-20.

14. van der Esch M, Steultjens M, Harlaar J, Knol D, Lems W, Dekker J. Joint proprioception, muscle strength, and functional ability in patients with osteoarthritis of the knee. Arthritis Rheum 2007;57:787-93.

15. Recommendations for the medical management of osteoarthritis of the hip and knee: 2000 update. American College of Rheumatology Subcommittee on Osteoarthritis Guidelines. Arthritis Rheum 2000;43:1905-15.

16. Şahin F, Büyükavcı R, Sağ S, Doğu B, Kuran B. Reliability and validity of the Turkish version of the berg balance scale in patients with stroke. Turk J Phys Med Rehab 2013;59:170-5.

17. Qutubuddin AA, Pegg PO, Cifu DX, Brown R, McNamee S, Carne W. Validating the Berg Balance Scale for patients with Parkinson's disease: a key to rehabilitation evaluation. Arch Phys Med Rehabil 2005;86:789-92.

18. Güngen C, Ertan T, Eker E, Yaşar R, Engin F. Reliability and validity of the standardized Mini Mental State Examination in the diagnosis of mild dementia in Turkish population. [Article in Turkish] Turk Psikiyatri Derg 2002;13:273-81.

19. Folstein MF, Folstein SE, McHugh PR. "Mini-mental state". A practical method for grading the cognitive state of patients for the clinician. J Psychiatr Res 1975;12:189-98.

20. Gallagher EJ, Liebman M, Bijur PE. Prospective validation of clinically important changes in pain severity measured on a visual analog scale. Ann Emerg Med 2001;38:633-8.

21. Angst F, Aeschlimann A, Steiner W, Stucki G. Responsiveness of the WOMAC osteoarthritis index as compared with the SF-36 in patients with osteoarthritis of the legs undergoing a comprehensive rehabilitation intervention. Ann Rheum Dis 2001;60:834-40.

22. Tüzün EH, Eker L, Aytar A, Daşkapan A, Bayramoğlu M. Acceptability, reliability, validity and responsiveness of the Turkish version of WOMAC osteoarthritis index. Osteoarthritis Cartilage 2005;13:28-33.

23. Berg KO, Wood-Dauphinee SL, Williams JI, Maki B. Measuring balance in the elderly: validation of an instrument. Can J Public Health 1992;83:7-11.

24. Berg K, Wood-Dauphinee S, Williams. The Balance Scale: reliability assessment with elderly residents and patients with an acute stroke. Scand J Rehabil Med 1995;27:27-36. 
25. Siggeirsdóttir K, Jónsson BY, Jónsson H Jr, Iwarsson S. The timed 'Up \& Go' is dependent on chair type. Clin Rehabil 2002;16:609-16.

26. Whitney SL, Wrisley DM, Marchetti GF, Gee MA, Redfern MS, Furman JM. Clinical measurement of sit-to-stand performance in people with balance disorders: validity of data for the Five-Times-Sit-to-Stand Test. Phys Ther 2005;85:1034-45.

27. Enright PL. The six-minute walk test. Respir Care 2003;48:783-5.

28. ATS Committee on Proficiency Standards for Clinical Pulmonary Function Laboratories. ATS statement: guidelines for the six-minute walk test. Am J Respir Crit Care Med 2002;166:111-7.

29. Barrack RL, Skinner HB, Cook SD, Haddad RJ Jr. Effect of articular disease and total knee arthroplasty on knee jointposition sense. J Neurophysiol 1983;50:684-7.

30. Sharma L, Pai YC, Holtkamp K, Rymer WZ. Is knee joint proprioception worse in the arthritic knee versus the unaffected knee in unilateral knee osteoarthritis? Arthritis Rheum 1997;40:1518-25.

31. Sharma L. Proprioceptive impairment in knee osteoarthritis. Rheum Dis Clin North Am 1999;25:299-314.

32. Sharma L, Cahue S, Song J, Hayes K, Pai YC, Dunlop D.
Physical functioning over three years in knee osteoarthritis: role of psychosocial, local mechanical, and neuromuscular factors. Arthritis Rheum 2003;48:3359-70.

33. Lord SR, Clark RD, Webster IW. Postural stability and associated physiological factors in a population of aged persons. J Gerontol 1991;46:69-76.

34. Colledge NR, Cantley P, Peaston I, Brash H, Lewis S, Wilson JA. Ageing and balance: the measurement of spontaneous sway by posturography. Gerontology 1994;40:273-8.

35. Pua Y1, Liang Z, Ong PH, Bryant AL, Lo NN, Clark RA. Associations of knee extensor strength and standing balance with physical function in knee osteoarthritis. Arthritis Care Res (Hoboken) 2011;63:1706-14.

36. Kim HS, Yun DH, Yoo SD, Kim DH, Jeong YS, Yun JS, et al. Balance control and knee osteoarthritis severity. Ann Rehabil Med 2011;35:701-9.

37. Ay S, Doğan ŞK, Evcik D. Is there an effective way to prescribe a home-based exercise program in patients with knee osteoarthritis? A randomized controlled study. Turk J Phys Med Rehab 2013;59:1-6.

38. Buğdaycı DS, Paker N, Tekdöş D, Topal K, Erbil E, Ersoy S. The functional status of knee in faller or non-faller female patients with knee osteoarthritis. Turk J Phys Med Rehab 2012;58:22-5. 